\title{
POSITIVE AND NEGATIVE ION FORMATION IN KETENE BY ELECTRON IMPACT
}

\author{
JACQUES E. COLLIN AND ROBERT LOCHT \\ Laboratoire d'Étude des États Ionisés, Institut de Chimie, Université de Liège, Sart-Tilman par Liège, 4000 \\ Liège (Belgium)
}

\section{ABSTRACT}

Dissociation processes leading to positive and negative ion formation in ketene are discussed on the basis of appearance potential measurements. All important positive and negative ions are examined.

For negative ions, only resonance dissociative attachment processes are considered. Excited electronic states of negative ions, in particular for $\mathrm{O}^{-}$, may explain the structure observed in the dissociative attachment efficiency curves.

\section{INTRODUCTION}

Ketene is an interesting and important intermediate product in a number of chemical reactions. It is one of the final products in the thermal decomposition of many oxygenated molecules such as acetone, acetic acid or acetic esters.

From a more fundamental point of view, a good knowledge of the physical chemistry of this molecule isoelectronic with $\mathrm{CO}_{2}$ is of interest because of its relative simplicity.

We studied the behaviour of ketene under electron impact in order to obtain useful thermodynamic data and information on the electron impact processes involved and on the nature of the various products, charged or neutral, which are formed in the dissociation reactions. Special attention has been paid to the formation of negative ions.

In the photolysis of ketene at $3100 \AA$, the primary step is very probably the production of $\mathrm{CO}$ and $\mathrm{CH}_{2}$ 1 , secondary reactions yielding $\mathrm{C}_{2} \mathrm{H}_{4}$ through reaction between a methylene radical and a ketene molecule $e^{2,3}$, rather than by methylene radical recombination ${ }^{1}$. This is partly due to the fact that the methylene radicals are mainly produced in their ground state which is the triplet ${ }^{3} \Sigma^{-}$; conversion to ${ }^{3} \Sigma_{\mathrm{g}}^{-}$of the first excited singlet ${ }^{1} A_{1}$ state, responsible for recombination, is only possible through collisional deactivation ${ }^{4}$. A recent flash photolysis study with a mass spectrometer by Kistiakowsky and $\mathrm{Kidd}^{6}$ showed fairly conclusively that $\mathrm{C}_{2} \mathrm{H}_{4}$ is effectively formed by the methylene-ketene reaction. Another possible primary step was recently proposed by Laufer ${ }^{7}$, i.e. the reaction

$$
\mathrm{CH}_{2} \mathrm{CO} \stackrel{h v}{\rightarrow} \mathrm{C}_{2} \mathrm{O}+\mathrm{H}_{2},
$$

as the result of a study of the photolysis of $\mathrm{CH}_{2} \mathrm{CO}-\mathrm{CD}_{2} \mathrm{CO}$ mixtures between $3130 \AA(3.96 \mathrm{eV})$ and $1470 \AA$ $(8.43 \mathrm{eV})$. As far as negative ions are concerned, the question arises whether various electronic states of negative ions can be observed in the dissociation processes.

\section{EXPERIMENTAL}

The ketene sample was prepared immediately before use, according to the method of William and Hurd $^{8}$, i.e. by continuous flow pyrolysis of acetone vapour on a nichrome wire. Although quite reactive, ketene does not polymerize easily when gaseous $\left(T_{\mathrm{B}}: 41{ }^{\circ} \mathrm{C} ; T_{\mathrm{F}}:-134{ }^{\circ} \mathrm{C}\right)$ and is stable as a liquid at $-20{ }^{\circ} \mathrm{C}$ in the absence of light. Purification of the product was performed by low temperature distillation, outgassing at $-80{ }^{\circ} \mathrm{C}$ and redistillation. The ketene sample was then stored in the gaseous state.

${ }^{1}$ Knox, Norrish and Porter ${ }^{5}$, however, considered the recombination as the main mechanism for the formation of ethylene. 
All mass spectra and negative ion ionization efficiency curves were obtained with a Varian-Mat $\mathrm{CH} 4$ mass spectrometer, equipped with a normal electron gun. Positive ion efficiency curves were obtained with an MS9-AEI mass spectrometer. The positive ion appearance potentials (AP) were determined by the extrapolated difference method, using $\mathrm{Kr}$ as a reference; the negative ion resonance capture AP'S were estimated by linear extrapolation (LE) of the low energy side of the resonance peak at the point of maximum slope as discussed elsewhere ${ }^{9}$, using $S / C S_{2}$ as reference ion. The operation of the ion source was the same as previously discussed ${ }^{9}$ so that no effect of the electron accelerating voltage or the ion focussing voltage on the electron beam energy spread was observed, and that kinetic energy discrimination effects were negligible, except perhaps for the negative hydrogen atom ion.

The assignment of errors involved in such measurements is always difficult. One may quote standard mean deviations as "reproducibility errors". These have not much significance since reproducibility is found experimentally to be always good, even though the efficiency curves show unfavourable curvature and may yield erroneous results. The reproducibility is often within $0.1 \mathrm{eV}$ or even $0.05 \mathrm{eV}$ for positive ions and within 0.2 to $0.1 \mathrm{eV}$ for negative ions in dissociative attachment (DA) processes. Obviously these figures have little meaning since the experimental value often corresponds to the vertical most probable transition and since the energy range of the latter in turn strongly depends on the shape of the potential surfaces and F-C zones concerned. Therefore we estimated the error range on the basis of a comparison between the shapes of the efficiency curves near threshold. For positive ions, if the shapes are similar, the quoted error is $0.2 \mathrm{eV}$; increasing departure from similarity, measured by the ratio of areas of the curved onsets leads to increasing estimated errors; the adopted values were the following: ratio $=1$, error: $0.2 \mathrm{eV}$; ratio 1.25 , error: $0.3 \mathrm{eV}$; ratio 1.5 , error: $0.4 \mathrm{eV}$; ratio 1.5 , error: $0.5 \mathrm{eV}$. For negative ions, the errors involved depend on the shape of the resonance curves; this has already been discussed by Locht and Momigny 9 . For narrow peaks the reproducibility is within $0.1 \mathrm{eV}$, but the uncertainty may increase to $0.3 \mathrm{eV}$ for broad peaks due to problems with linear extrapolation. For identical peak shapes, the reproducibility error was adopted since the intrinsic error will be small ${ }^{9}$. For other cases, the error was based on the half-width ratio $w_{i} / w_{\text {ref }}$ where $\mathrm{w}_{\mathrm{i}}$ and $w_{\text {ref }}$ are the half-height width of the peak for the ion under study and the reference ion respectively. For ratio values between 1 and 1.2,1.2 and 1.4 or greater than 1.4, the adopted errors were $0.3,0.4$ or $0.6 \mathrm{eV}$ respectively. The results are summarized in Tables 1 and 2 .

TABLE 1 ABUNDANCES AND APPEARANCE POTENTIALS OF POSITIVE IONS IN KETENE

\begin{tabular}{cccc}
\hline$m / e$ & Formula & $\begin{array}{c}\text { Abundance }(\% \\
\text { total ionization) }\end{array}$ & $\begin{array}{c}\text { Appearance } \\
\text { potential (eV) }\end{array}$ \\
\hline 12 & $\mathrm{C}$ & 2.19 & - \\
13 & $\mathrm{CH}$ & 2.90 & - \\
14 & $\mathrm{CH}_{2}$ & 33.23 & $13.8 \pm 0.2$ \\
28 & $\mathrm{CO}$ & 7.78 & $13.57 \pm 0.3$ \\
29 & $\mathrm{COH}$ & 3.77 & $16.07 \pm 0.4$ \\
40 & $\mathrm{C}_{2} \mathrm{OH}$ & 2.72 & \\
41 & $\mathrm{C}_{2} \mathrm{OH}$ & 11.98 & $14.91 \pm 0.3$ \\
42 & $\mathrm{COCH}_{2}$ & 35.53 & $9.99 \pm 0.2$ \\
\hline
\end{tabular}


TABLE 2 NEGATIVE ION APPEARANCE POTENTIALS IN KETENE (IN eV)

\begin{tabular}{ccc}
\hline$m / e$ & Formula & Resonance processes \\
\hline 1 & $\mathrm{H}$ & $5.41 \pm 0.15$ \\
& & $8.5 \pm 0.3$ \\
13 & $\mathrm{CH}$ & $9.1 \pm 0.3$ \\
14 & $\mathrm{CH}_{2}$ & $2.9 \pm 0.4$ \\
& & $4.6 \pm 0.6$ \\
& & $11.5^{*}$ \\
16 & $\mathrm{O}$ & $3.95 \pm 0.2$ \\
& & $6.48 \pm 0.2$ \\
24 & $\mathrm{C}_{2}$ & $8.95 \pm 0.2$ \\
& & $8.57 \pm 0.4$ \\
25 & $\mathrm{C}_{2} \mathrm{H}$ & $6.26 \pm 0.3$ \\
& & $8.84 \pm 0.3$ \\
40 & $\mathrm{C}_{2} \mathrm{O}$ & $5.22 \pm 0.2$ \\
& & $8.89 \pm 0.2$ \\
41 & $\mathrm{C}_{2} \mathrm{HO}$ & $2.03 \pm 0.2$ \\
$*$ Estimated position of maximum.
\end{tabular}

\section{DISCUSSION OF RESULTS.}

I. Positive Ions.

\section{Ionization potential}

The measured ionization potential (IP) of ketene $9.99 \pm 0.2 \mathrm{eV}$, is considerably higher than the spectroscopic value $9.61 \mathrm{eV}$ of Price et al. ${ }^{10}$ or the electron impact value $9.4 \mathrm{eV}$ of Long and Friedman ${ }^{11}$. The latter value is anomalously low, $0.21 \mathrm{eV}$ lower than the spectroscopic result. Our result, on the other hand, suggests that the Franck-Condon most probable transition does not correspond to the adiabatic IP, in contrast to what is usual in the case of ketones. It may also mean that the removed electron has not the clear-cut oxygen non-bonding character generally assumed for ketones.

\section{Appearance potentials and thermodynamic data}

(a) The $\mathrm{CH}_{2}^{+}$ion $(\mathrm{AP}: 13.91 \mathrm{eV})$

The ionization efficiency curve for $\mathrm{CH}_{2}^{+}$is very similar to that observed for the $\mathrm{Kr}$ reference ion, suggesting that no excess energy is involved. Taking $\mathrm{AP}\left(\mathrm{CH}_{2}{ }^{+}\right)$as a minimum value, in close agreement with the result of Long and Friedman ${ }^{11}, 13.8 \mathrm{eV}$, a straightforward calculation gives $\Delta H_{\mathrm{f}}\left(\mathrm{CH}_{2}{ }^{+}\right)=14.42 \mathrm{eV}$. The most recent and probably most reliable data for this value are those of Dibeler et al. ${ }^{12}$ and of Chupka and Lifshitz ${ }^{13}$ obtained by photoionization of $\mathrm{CH}_{4}$ and $\mathrm{CH}_{3}$ respectively. The values are 93.9 and $91.9 \mathrm{kcal} / \mathrm{mole}$ respectively, the latter being probably the best value. It is much higher than the previously proposed value of $57.6 \mathrm{kcal} / \mathrm{mole}$ of Bernecker and Long ${ }^{14}$, but close to the estimated $90 \mathrm{kcal} / \mathrm{mole}$ of $\mathrm{Kerr}^{15}$.

Using Chupka's result, we deduce from $\mathrm{AP}\left(\mathrm{CH}_{2}{ }^{+}\right)$the value $10.43 \mathrm{eV}$ for the first IP of $\mathrm{CH}_{2}$, in close agreement with the spectroscopic result $10.39 \mathrm{eV}$ of Herz-berg ${ }^{16}$. This suggests that the same electronic state is involved. According to Herz-berg ${ }^{17}$, this is a ${ }^{2} \Pi_{u}$ excited linear state, probably situated some $0.3 \mathrm{eV}$ above the ground bent state, by analogy with the isoelectronic $\mathrm{BH}_{2}$ molecule.

(b) The $\mathrm{CHO}^{+}$ion (A.P. $\left.16.07 \mathrm{eV}\right)$

A straightforward thermochemical calculation, using $\Delta H_{\mathrm{f}}(\mathrm{CH})=6.16 \mathrm{eV}^{2}$, leads to $\Delta H_{\mathrm{f}}\left(\mathrm{CHO}^{+}\right)=9.33$ $\mathrm{eV}$. This value is $0.7 \mathrm{eV}$ higher than the latest published value $8.6 \mathrm{eV}$ of Haney and Franklin ${ }^{19}$, as obtained by measurements of AP'S for oxygenated ions combined with ion translational energies. It is thus probable that $\mathrm{CHO}^{+}$appears in ketene with a translational energy of the order of $0.7 \mathrm{eV}$. This seems to be confirmed by the

\footnotetext{
${ }^{2}$ Except where otherwise stated, all thermodynamical data were taken from ref. 18
} 
observed extended curvature of the curve (quoted error: $0.4 \mathrm{eV}$ ). It is concluded ${ }^{3}$ that dissociation is taking place well above the dissociation limit.

(c) The $\mathrm{CHCO}^{+}$ion $(\mathrm{AP}: 14.9 \mathrm{eV})$

From $\mathrm{AP}\left(\mathrm{CHCO}^{+}\right)=14.9_{1} \mathrm{eV}$, one calculates $\Delta H_{\mathrm{f}}\left(\mathrm{CHCO}^{+}\right)=12.0 \pm 0.3 \mathrm{eV}$. Assuming the structure $\mathrm{CH}=\mathrm{CO}$ for the $\mathrm{C}_{2} \mathrm{HO}$ radical and taking $\mathrm{D}(\mathrm{H}-\mathrm{CHCO})=4.48 \mathrm{eV}^{20}$, one obtains $\Delta H_{\mathrm{f}}(\mathrm{CHCO})=1.59 \mathrm{eV}$ and, by combination of these data, an upper limit of $10.4 \mathrm{eV}$ is found for IP(CHCO). There is until now no direct experimental determination to which this value could be compared.

\section{Negative ions}

\section{(a) Introductory remark}

Ideally, a satisfactory treatment would require that the experimental data be obtained with monoenergetic electrons in order to understand the significance of the resonance curve shape, notably from the standpoint of knowing whether the minimum resonance threshold corresponds to zero-kinetic energy ions or not.

Our measurements were however made with a Nier-type normal electron gun. Deconvolution of the experimental data, although desirable, is not possible due to the unfavourable signal-to-noise ratio. This situation was discussed previously in detail by Locht and Momigny ${ }^{9}$. These authors, in an attempt to treat diatomics, have applied a convolution method, using the experimentally determined electron energy distribution, to the analysis of DA resonance curves. From the peak shape, they deduce information on the type of transition involved.

The situation is obviously more complicated for polyatomics but it may be useful to apply qualitatively the same principles to the analysis of the data.

The following negative ions were observed and examined in the case of ketene: $\mathrm{H}^{-}, \mathrm{CH}^{-}, \mathrm{CH}_{2}^{-}, \mathrm{O}^{-}, \mathrm{C}_{2}^{-}$, $\mathrm{C}_{2} \mathrm{H}^{-}, \mathrm{C}_{2} \mathrm{O}^{-}$and $\mathrm{CHCO}^{-}$. All these ions are produced both in DA process and in ion-pair reactions. Only the DA resonances will be discussed here.

\section{(b) The $H$ ion}

Two resonance processes are observed (Fig. 1), appearing at $5.41 \mathrm{eV}$ and $8.5 \mathrm{eV}\left(\mathrm{LE}^{4}\right)$ respectively, their relative intensities at peak maximum being in the ratio 1:3.

Fig. 1. Dissociative attachment in ketene: formation of ion of mass 1.

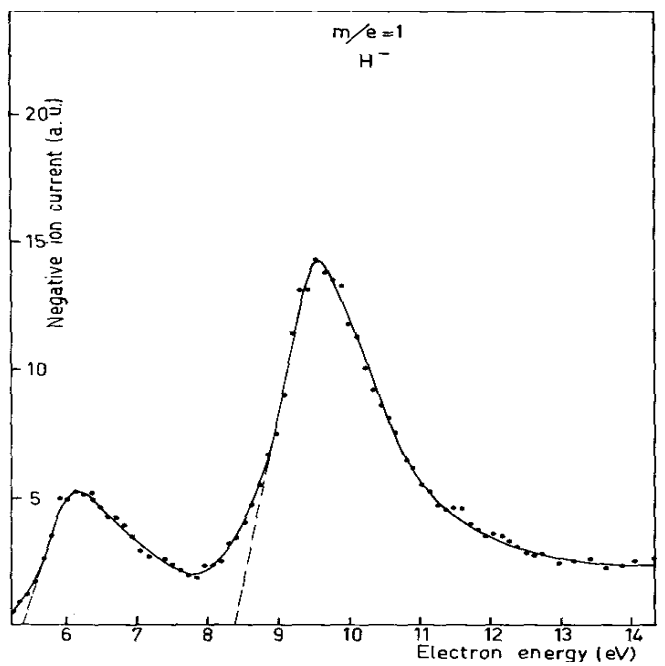

\footnotetext{
${ }^{3} \mathrm{An}$ ion-pair reaction giving $\mathrm{CHO}^{+}+\mathrm{CH}^{-}$may be excluded since the only process in the $\mathrm{CH}^{-}$efficiency curve which might be interpreted as an ion-pair process was found at the much higher energy $21.2 \mathrm{eV}$.

${ }^{4} \mathrm{LE}=$ linear extrapolation, maximum slope on the low-energy side of the peak.
} 
The $5.41 \mathrm{eV}$ peak shows considerable asymmetry, the width of the high energy side being approximately twice that of the low energy side. The shape of this curve is similar to that of $\mathrm{H}^{-} / \mathrm{H}_{2}$. According to Locht and Momigny ${ }^{9}$ it is typical of a transition to the negative ion potential curve partly above and partly below the dissociation limit and is referred to as a "type b" process, following the nomenclature of these authors. As a result, if no discrimination effects interfere for $\mathrm{H}^{-}$, the minimum value should correspond to the asymptotic dissociation limit.

The only process having such a low AP is

$$
\mathrm{CH}_{2} \mathrm{CO}+\mathrm{e} \rightarrow\left(\mathrm{CH}_{2} \mathrm{CO}\right)^{-} \rightarrow \mathrm{COCH}^{*}+\mathrm{H}^{-}
$$

Assuming $\mathrm{CHCO}$ in its ground state $\left(\Delta H_{f}=1.59 \mathrm{eV}\right.$, see above), an $\operatorname{AP}\left(\mathrm{H}^{-}\right)=3.68 \mathrm{eV}$ is calculated. Therefore, since after the peak shape no kinetic energy is involved at threshold, we conclude that $\mathrm{COCH}$ appears in an excited state $1.73 \mathrm{eV}$ above ground state. (For comparison, the energy separation is $3.22 \mathrm{eV}$, between the first excited state and the ground state in ketene itself ${ }^{17}$.)

The $8.5 \mathrm{eV}$ peak apparently also belongs to type $\mathrm{b}$ processes, with a lower limit corresponding to the minimum dissociation limit. For the reaction

$$
\mathrm{CH}_{2} \mathrm{CO}+\mathrm{e} \rightarrow \mathrm{CO}+\mathrm{CH}+\mathrm{H}^{-}
$$

$\mathrm{AP}\left(\mathrm{H}^{-}\right)$is calculated to be $7.21 \mathrm{eV}$, all other possible processes having AP'S greater than $8.5 \mathrm{eV}^{5}$. The difference of $1.3 \mathrm{eV}$ is not high enough to be explained by electronic excitation of $\mathrm{CO}$ or $\mathrm{CH}$ (first excited states at 8.07 and $2.88 \mathrm{eV}$ above ground state respectively ${ }^{17}$ ).

For both processes, the most probable transition apparently corresponds to the appearance of fragments with kinetic energy.

When evaluated by the half-width method of Locht and Momigny ${ }^{9}$, using these author's curves, the total kinetic energy width is about $1.7 \mathrm{eV}$ for process (1) and about $1.9 \mathrm{eV}$ for process (2).

\section{(c) The $\mathrm{CH}$ ion}

Only one attachment process is observed, at $9.10 \mathrm{eV}$, and the peak shape is fairly symmetrical although quite broad (half-width: $1.4 \mathrm{eV}$ ). This type of behaviour is typical of type c transition in Locht and Momigny's nomenclature $^{9}$, i.e. a transition completely in the repulsive part of the potential curve/or surface, in a region where the linear or planar approximation is good. The estimated total kinetic energy is about $3 \mathrm{eV}$.

Two possible processes are

$$
\begin{aligned}
\mathrm{CH}_{2} \mathrm{CO}+\mathrm{e} & \rightarrow \mathrm{CH}^{-}+\mathrm{CO}+\mathrm{H} \\
& \rightarrow \mathrm{CH}^{-}+\mathrm{COH}
\end{aligned}
$$

The minimum calculated AP'S are 4.80 and $3.68^{6} \mathrm{eV}$ respectively i.e. very much lower than the observed AP. The excess energies would be 4.3 and $5.4 \mathrm{eV}$ respectively. First excitation energies are $10.15 \mathrm{eV}$ for $\mathrm{H}$ (ref. 21), $8.07 \mathrm{eV}$ for $\mathrm{CO}$ (ref. 22), $1.51 \mathrm{eV}$ for $\mathrm{COH}$ (ref. 17) and $3.1 \mathrm{eV}$ for $\mathrm{CH}^{-}$(ref. 23). Excitation of $\mathrm{H}$ or $\mathrm{CO}$ is therefore excluded. Process (3) leading to the formation of the stable CO molecule seems more likely. It then follows that the excess energy is either used for electronic excitation of $\mathrm{CH}^{-}$and kinetic energy of the fragments, of for vibra-tional excitation and kinetic energy, or for kinetic energy alone. Electronic excitation of $\mathrm{CH}^{-}$seems unlikely since it would leave only $1.2 \mathrm{eV}$ for kinetic energy, contrary to the estimated value above. We therefore assume that $\mathrm{CH}^{-}$appears in its ground state, possibly vibrationally excited, and that the excess energy is mainly translational.

\footnotetext{
${ }^{5}$ With the possible exception of the reaction $\mathrm{CH}_{2} \mathrm{CO}+\mathrm{e} \rightarrow \mathrm{C}_{2} \mathrm{O}+\mathrm{H}+\mathrm{H}^{-}\left(2^{\prime}\right)$ for which the calculated minimum $\operatorname{AP}(\mathrm{H}-)=6.02 \mathrm{eV}$.

${ }^{6}$ Using $\Delta H_{\mathrm{f}}\left(\mathrm{CH}^{-}\right)=3.05 \mathrm{eV}$ as determined by $\operatorname{Locht}^{23}$ in a study of the formation of $\mathrm{CH}^{-}$in methane.
} 
Fig. 2. Dissociative attachment in ketene: formation of ion of mass 13.

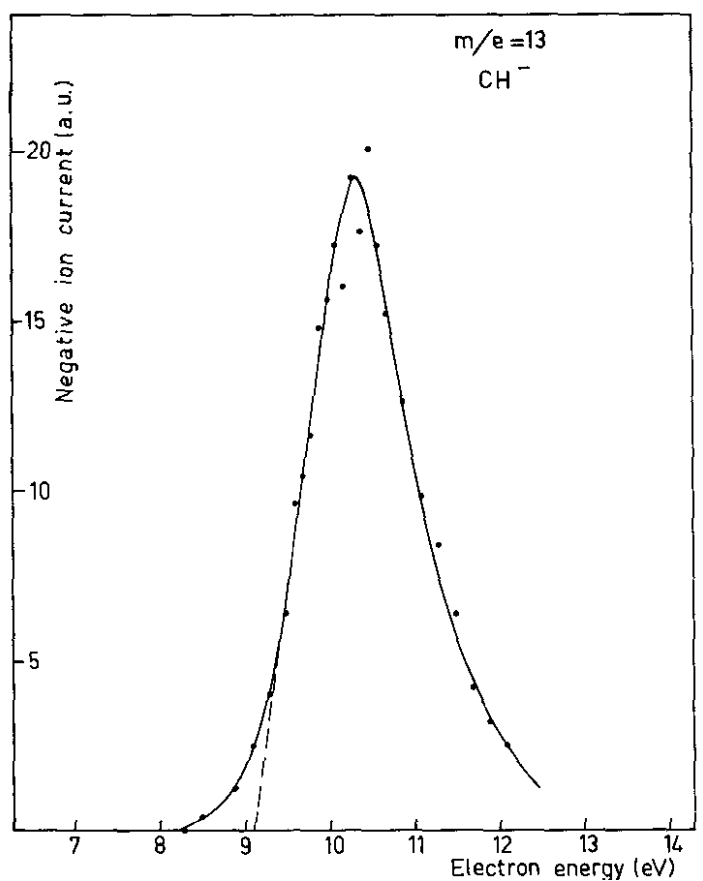

(d) The $\mathrm{CH}_{2}^{-}$ion

The case of $\mathrm{CH}_{2}{ }^{-}$is interesting, for the only dissociation path to be considered is

$$
\mathrm{CH}_{2} \mathrm{CO}+\mathrm{e} \rightarrow \mathrm{CH}_{2}^{-*}+\mathrm{CO}^{* *}
$$

where $\mathrm{CH}_{2}{ }^{-}$and/or $\mathrm{CO}$ may be in excited electronic states.

The experimental efficiency curve (Fig. 3) shows three distinct attachment processes; the AP'S for the first two processes are 2.9 and $4.6 \mathrm{eV}$; the third process gives rise to a very broad peak for which an LE threshold value is meaningless; its maximum appears around $11.5 \mathrm{eV}$. These various potentials clearly indicate the formation of electronically excited species. It should be noted that very narrow resonance peaks are observed for the 2.9 and $4.6 \mathrm{eV}$ processes. They are slightly asymmetrical on the low energy side, which might be typical of type c processes ${ }^{9}$ in an FC region where the curves or surfaces are rather flat, or for a transition occur-ring mostly below the dissociation limit. This latter situation seems more likely in view of the narrowness of the peaks. The corresponding total kinetic energy widths are 1.4 and $1.3 \mathrm{eV}$ approximately.

The minimum calculated AP for $\mathrm{CH}_{2}^{-}$in reaction (5) requires the knowledge of the heat of formation of $\mathrm{CH}_{2}{ }^{-}$for which the value deduced from $\mathrm{AP}\left(\mathrm{CH}_{2}^{-}\right)$in methane is $4.31 \mathrm{eV}^{23}$. This, combined with $\Delta H_{f}(\mathrm{CO})=-$ $1.146 \mathrm{eV}$ and $\Delta H_{f}\left(\mathrm{CH}_{2} \mathrm{CO}\right)=-0.63 \mathrm{eV}$ gives $\mathrm{AP}\left(\mathrm{CH}_{2}{ }^{-}\right)=3.79 \mathrm{eV}$, i.e. $0.9 \mathrm{eV}$ higher than the measured value.

This suggests that the $\mathrm{CH}_{2}{ }^{-}$ion observed in ketene has a heat of formation lower than the value $4.31 \mathrm{eV}$ obtained for $\mathrm{CH}_{2}^{-} / \mathrm{CH}_{4}$. It is possible that $\mathrm{CH}_{2}{ }^{-} / \mathrm{CH}_{4}$ was in an electronically excited state, or that it was endowed with at least $0.9 \mathrm{eV}$ of rotational-vibrational excitation. From our measurement, we conclude that, for its ground state, $\Delta H_{\mathrm{f}}\left(\mathrm{CH}_{2}^{-}\right) \leq 3.4 \mathrm{eV}$.

The next process at $4.6 \mathrm{eV}$ refers to another electronic state of $\mathrm{CH}_{2} \mathrm{CO}^{-}$, although it might lead to the same products.

It is possible that it corresponds to an electronically or vibrationally excited state of $\mathrm{CH}_{2}^{-}$, although this would be expected to have a very short lifetime. We have at present no way of making a choice.

The third process has its maximum at $11.5 \mathrm{eV}$ and begins to appear around $10.1 \mathrm{eV}$. One calculates $\mathrm{AP}\left(\mathrm{CH}_{2}{ }^{-}\right)=9.5 \mathrm{eV}$, assuming $\Delta H_{f}\left(\mathrm{CH}_{2}^{-}\right) \leq 3.4 \mathrm{eV}$ as shown above, and $\mathrm{CO}$ in its first excited state $A^{1} \Pi, 8.03 \mathrm{eV}$ 
above the ground $\operatorname{state}^{7}$ after the recent electron energy loss experiments of Lassettre et al. ${ }^{24}-^{8}$. Within error limits, this suggests that the process having its maximum at $11.5 \mathrm{eV}$ probably corresponds to the appearance of a $\mathrm{CO}$ molecule in its ${ }^{1} \Pi$ excited state.

Fig. 3. Dissociative attachment in ketene: formation of ion of mass 14.

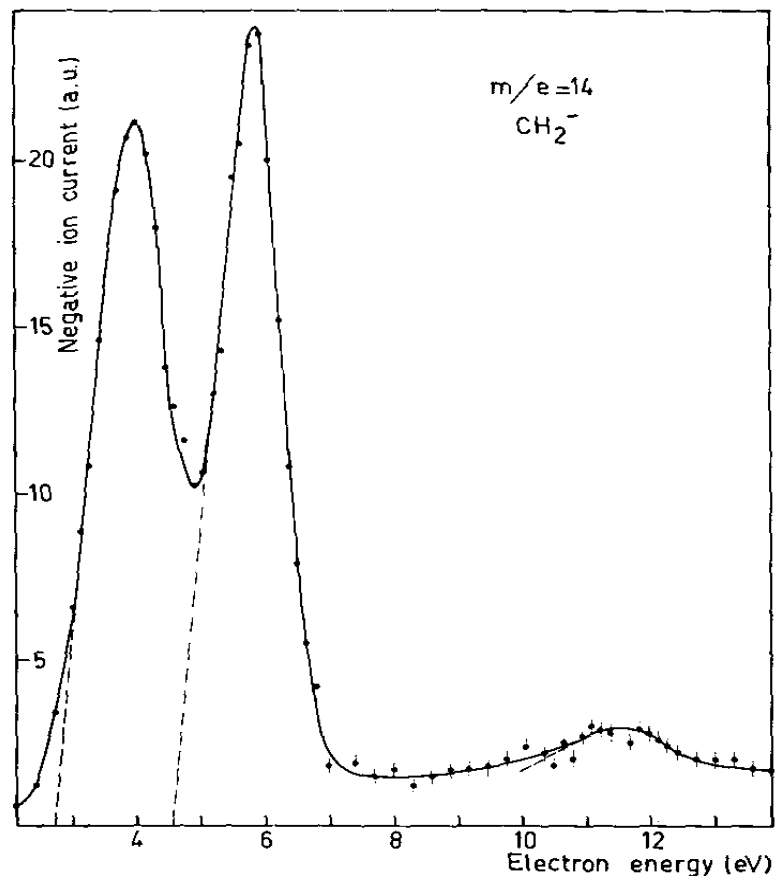

(e) The $O^{-}$ion

It is clear from Fig. 4 that three important resonance reactions are responsible for the formation of negative $\mathrm{O}^{-}$ions in ketene, with their minimum AP'S at 3.95, 6.48 and $8.95 \mathrm{eV}$.

Of the various attachment processes, only two must be considered as possible ways of reaction, all others requiring too high energies. These are

$$
\mathrm{CH}_{2} \mathrm{CO}+\mathrm{e} \rightarrow \mathrm{CH}_{2} \mathrm{C}:+\mathrm{O}^{-}
$$

and

$$
\mathrm{CH}_{2} \mathrm{CO}+\mathrm{e} \rightarrow \mathrm{CH}: \mathrm{CH}+\mathrm{O}^{-}
$$

Formation of the diradical $\mathrm{CH}_{2} \mathrm{C}$ : seems much less likely than the appear-ance of the stable acetylene molecule. Unfortunately no value for $\Delta H_{(}\left(\mathrm{CH}_{2} \mathrm{C}\right.$ : $)$ is known for a calculation to be made. In the case of reaction (7) however, the mini-mum $\mathrm{AP}\left(\mathrm{O}^{-}\right)$calculated using JANAF Thermochemcial Tables is $4.03 \mathrm{eV}$. This corresponds, within the error limits, to the experimental $\mathrm{AP}\left(\mathrm{O}^{-}\right)=3.95 \mathrm{eV}$ and strongly favours mechanism (7) as a source of $\mathrm{O}^{-}$ions, with the acetylene molecule in its ground state.

The two processes at $6.48 \mathrm{eV}$ and $8.95 \mathrm{eV}$ cannot be ascribed to the formation of excited electronic states of acetylene, since the lowest of those is $6.23 \mathrm{eV}$ above the ground state ${ }^{20}$.

These peaks are quite narrow, suggesting that no important kinetic energy is involved in the process. If

\footnotetext{
${ }^{7}$ This gives $\Delta H_{\mathrm{f}}\left(\mathrm{CO}, A^{1} \Pi\right)=6.88 \mathrm{eV}$.

${ }^{8} \mathrm{We}$ found the same value using the $\mathrm{SF}_{6}$ scavenger technique (Collin and Hubin-Franskin, to be published).
} 
this conclusion is correct, it suggests that the two processes correspond to the appearance of excited electronic states of $\mathrm{O}^{-}$, rather than a transition to a temporary excited electronic state of $\mathrm{CH}_{2} \mathrm{CO}$, leading to $\mathrm{O}^{-}$and $\mathrm{C}_{2} \mathrm{H}_{2}$ ground states, since in this latter case kinetic energy of the order of $2.5 \mathrm{eV}$ and $5 \mathrm{eV}$ respectively would be expected. Excited electronic states of negative ions are not frequent and normally have very short lifetimes. Our results are therefore unexpected, although very recently such long lived excited states for the $\mathrm{S}^{-}$ion have been suggested by Yergey and Franklin ${ }^{25}$. The excitation energies of $\mathrm{O}^{-}$, deduced from our measurements are then $2.53 \mathrm{eV}$ and $5.0 \mathrm{eV}$, assuming no vibrational excitation of the acetylene molecule.

A fourth process is detectable around $12 \mathrm{eV}$ but its small cross section does not allow a reliable value to be proposed.

Fig. 4. Dissociative attachment in ketene: formation of ion of mass 16.

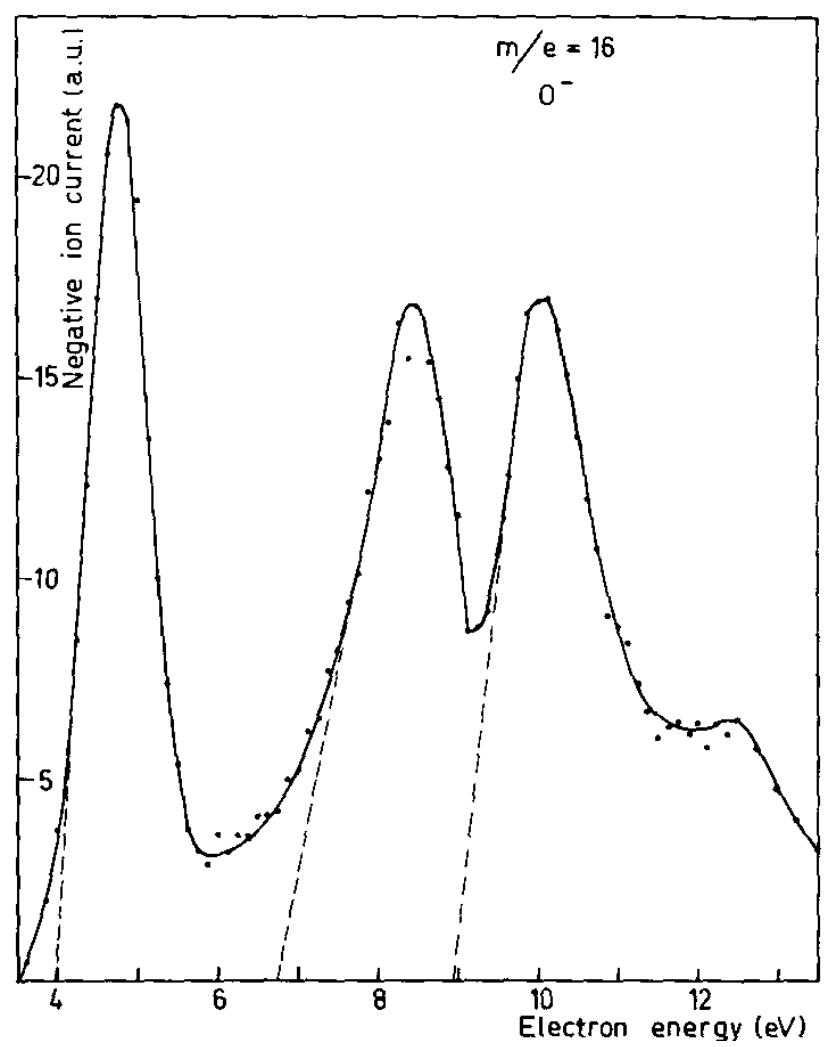

(f) The $C_{2}^{-}$ion

The attachment curve (Fig. 5) for this ion shows at least two important processes at 6.57 and $8.79 \mathrm{eV}$ respectively which may be tentatively discussed on the basis of $\Delta H_{f}\left(C_{2}^{-}\right)=6.57 \mathrm{eV}$ as recently deduced experimentally by $\operatorname{Locht}^{23}-{ }^{9}$, For thermochemical reasons only the reaction (8)

$$
\mathrm{CH}_{2} \mathrm{CO}+\mathrm{e} \rightarrow \mathrm{C}_{2}^{-}+\mathrm{H}_{2} \mathrm{O}
$$

can be taken into account. Its minimum AP is $4.70 \mathrm{eV}$ considerably lower than the experimental result. The broadness of the resonance peaks confirms that much kinetic energy is probably involved. The first excited state of $\mathrm{H}_{2} \mathrm{O}$ being $6.27 \mathrm{eV}$ above the ground state ${ }^{17}$, the occurrence of the two peaks might correspond, at least partly, to the formation of $C_{2}^{-}$ions in one of their excited electronic states.

\footnotetext{
${ }^{9}$ There is some doubt about the value of $\Delta H_{\mathrm{f}}\left(C_{2}^{-}\right)$. The recommended value of JANAF tables is $5.6 \mathrm{eV}$ but this is based on a very approximate value of $\operatorname{IP}\left(\mathrm{C}_{2}^{-}\right)=3.1 \pm 1 \mathrm{eV}$. The more recent value deduced by Locht from a study of the appearance of $\mathrm{C}_{2}^{-}$in acetylene and vinyl halides is within the error limits of the JANAF data.
} 
Fig. 5. Dissociative attachment in ketene: formation of ion of mass 24.

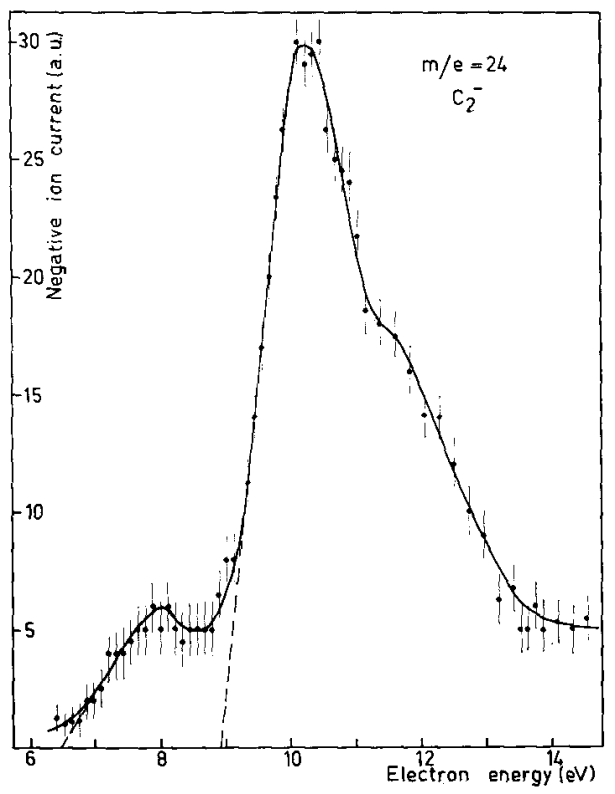

(g) The $\mathrm{C}_{2} \mathrm{H}$ ion

Two resonance processes are detected at 6.26 and $8.84 \mathrm{eV}$, the $6.26 \mathrm{eV}$ peak showing considerable asymmetry on the low energy side suggesting that the AP is a minimum value. Using $\Delta H_{\mathrm{f}}\left(\mathrm{C}_{2} \mathrm{H}^{-}\right)=2.80 \mathrm{eV}^{10}$ or $4.71 \mathrm{eV}$, recently determined by Locht ${ }^{23}$, one calculates for processes (9) and (10)

$$
\begin{aligned}
\mathrm{CH}_{2} \mathrm{CO}+\mathrm{e} & \rightarrow \mathrm{C}_{2} \mathrm{H}^{-}+\mathrm{OH} \\
& \rightarrow \mathrm{C}_{2} \mathrm{H}^{-}+\mathrm{O}+\mathrm{H}
\end{aligned}
$$

3.81 and $8.27 \mathrm{eV}$ for the respective AP's, assuming $\mathrm{C}_{2} \mathrm{H}^{-}$in its ground state, or 5.72 and $10.18 \mathrm{eV}$ if this ion is in its first excited state. Obviously AP $=6.26 \mathrm{eV}$ must correspond to (9); owing to the shape of the curve, it might correspond to the first excited state of $\mathrm{C}_{2} \mathrm{H}^{-}$. If this interpretation is correct, the second AP must be assigned to (10) and involves some excess kinetic energy.

\section{(h) The $\mathrm{C}_{2} \mathrm{O}^{-}$ion}

The complex curve for $\mathrm{C}_{2} \mathrm{O}^{-}$will not be discussed for lack of information on the heat of formation of this ion. Three distinct processes are involved (AP's given in Table 2).

\section{(i) The $\mathrm{CHCO}^{-}$ion}

Most $\mathrm{CHCO}^{-}$ions are formed by a single and sharply defined resonance peak at $2.03 \mathrm{eV}$. The only possible reaction is obviously

$$
\mathrm{CH}_{2} \mathrm{CO}+\mathrm{e} \rightarrow \mathrm{CHCO}^{-}+\mathrm{H}
$$

Since the first excited state of $\mathrm{H}$ is $10.15 \mathrm{eV}$ above the ground state, it is concluded that the hydrogen atoms appear in their fundamental ${ }^{2} S$ state. Therefore the heat of formation of $\mathrm{CHCO}^{-}$is calculated to have a maximum value of $-0.56 \mathrm{eV}$, in-dicating that this ion is a stable negative ion.

\footnotetext{
${ }^{10}$ Assigned to ground state.
} 
Pubished in: International journal of Mass Spectrometry and Ions Physics (1970), vol.3 , pp. 465-478

Status: Postprint (Author's version)

Fig. 6. Dissociative attachment in ketene: formation of ion of mass 25.

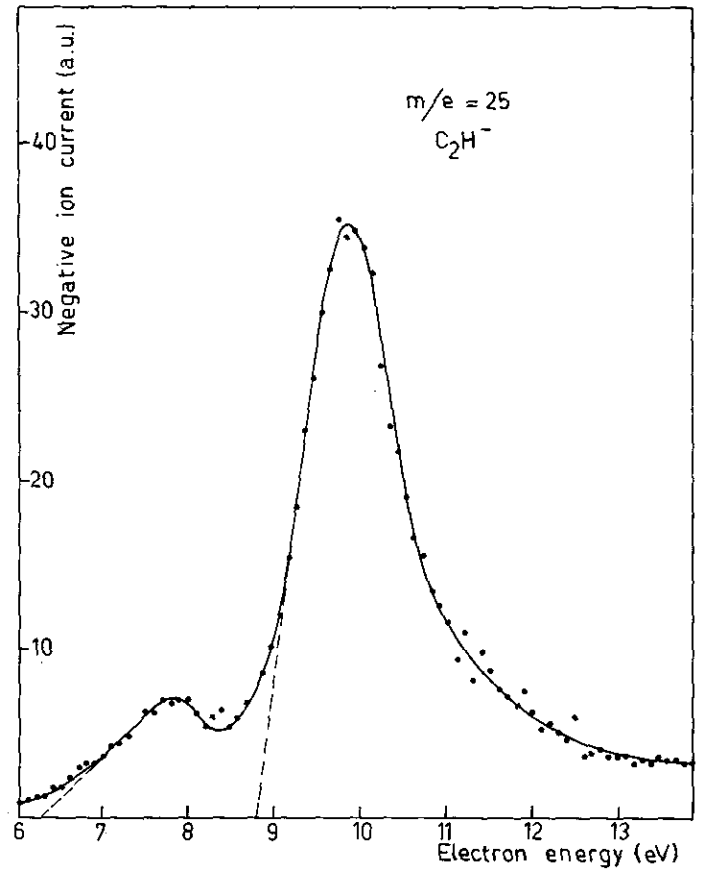

Fig. 7. Dissociative attachment in ketene: formation of ion of mass 40.

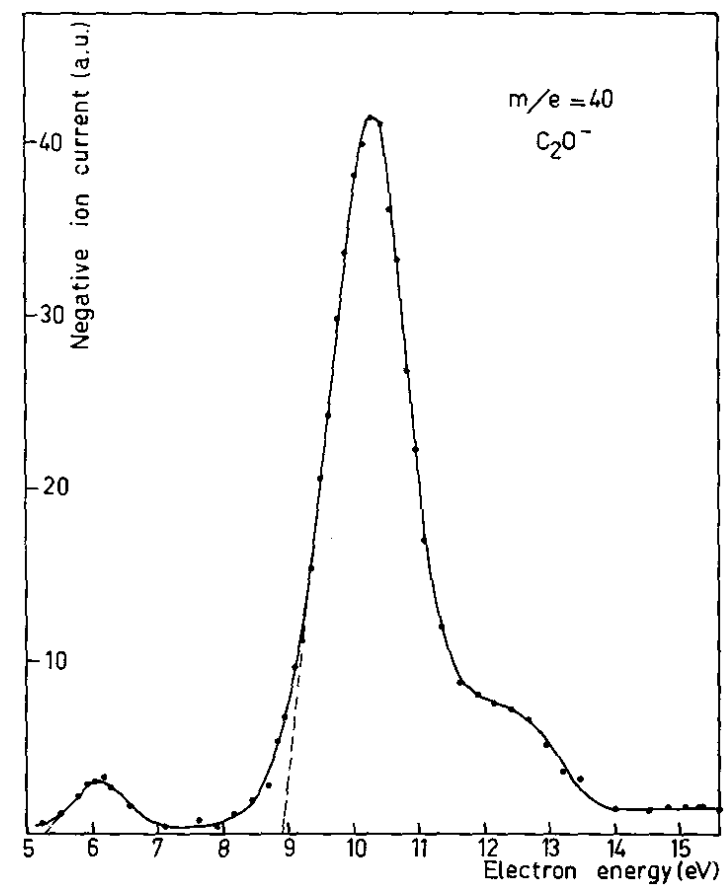


Fig. 8. Dissociative attachment in ketene: formation of ion of mass 41.

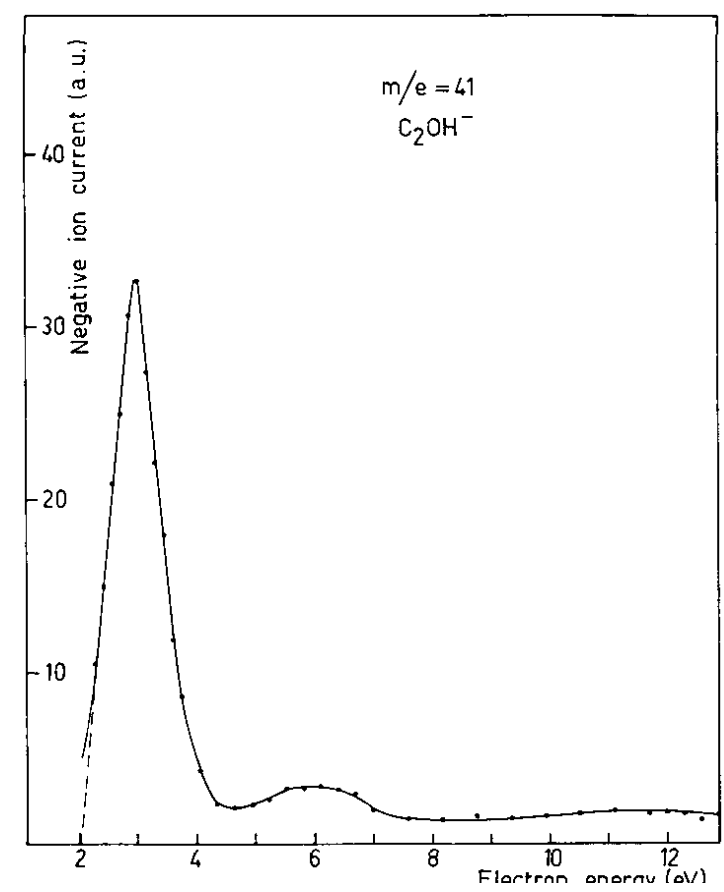

\section{ACKNOWLEDGEMENTS}

We thank Professor L. D'Or for his constant interest in our work. This research was partly sponsored by the Fonds de la Recherche Fondamentale Collective.

\section{REFERENCES}

1 G. B. Kistiakowsky and N. W. Rosenberg, J. Am. Chem. Soc, 72 (1950) 321.

2 C. Ross And G. B. Kistiakowsky, J. Am. Chem. Soc, 56 (1934) 1112.

3 R. G. W. Norrish and H. G. Crone, J. Chem. Soc., (1933) 1533; J. Am. Chem. Soc., 56 (1934) 1634.

4 T. W. Eder, R. W. Carr And J. W. Koenst, Chem. Phys. Lett., 3 (1969) 520.

5 K. Knox, R. G. W. Norrish And G. Porter, J. Chem. Soc, (1952) 1477.

6 G. B. Kistiakowsky And B. Kidd, J. Am. Chem. Soc, 79 (1957) 4825.

7 A. H. Laufer, J. Phys. Chem., 73 (1969) 959.

8 R. William and S. Hurd, J. Org. Chem., 5 (1940) 122.

9 R. Locht And J. Momigny, Int. J. Mass Spectrom. Ion Phys., 2 (1969) 425.

10 W. C. Price, J. P. Teegan And A. D. Walsh, J. Chem. Soc, (1951) 920.

11 F. A. Long and L. Friedman, J. Am. Chem. Soc, 75 (1953) 2837. 
Pubished in: International journal of Mass Spectrometry and Ions Physics (1970), vol.3 , pp. 465-478

Status: Postprint (Author's version)

12 V. H. Dibeler, M. Krauss, R. M. Reese and F. N. Harlee, J. Chem. Phys., 42 (1965) 3791.

13 W. A. Chupka And C. Lifshitz, J. Chem. Phys., 48 (1968) 1109.

14 R. R. Bernecker And F. A. Long, J. Phys. Chem., 65 (1961) 1565.

15 J. A. KERR, Chem. Rev., 66 (1966) 465.

16 G. Herzberg, Can. J. Phys., 39 (1961) 1511.

17 G. HerZBERG, Molecular Spectra and Molecular Structure. Vol. III. Electronic Spectra of Pol-atomic Molecules, Van Nostrand, New York, 1966.

18 JANAF Thermochemical Tables, U.S. Dept. of Commerce, N.B.S. Dow Chemical Co., Midland, Mich., 1965.

19 M. A. Haney AND J. L. FrankLin, Trans. Faraday Soc, 65 (1969) 1794.

20 L. Gero and J. G. Valatin, J. Chem. Phys., 16 (1948) 1016.

21 G. HerZBErg, Atomic Spectra and Atomic Structure, Van Nostrand, New York, 1945.

22 G. HerzBerg, Molecular Spectra and Molecular Structure. Vol. II. Diatomic Molecules, Van Nostrand, New York, 1950.

23 R. LOCHT, unpublished experiments, 1968.

24 V. D. Meyer, A. Skerbele And E. N. Lassettre, J. Chem. Phys., 43 (1965) 805.

25 A. L. Yergey AND J. L. FrankLin, 17th ASTM Annual Conference on Mass Spectrometry, Dallas, May 1969. 